\title{
Iminodiacetic acid modified kenaf fiber for waste water treatment
}

\begin{abstract}
In the present study, iminodiacetic acid (IDA)-modified kenaf fiber, K-IDA formed by the chemical modification of plant kenaf biomass was tested for its efficacy as a sorbent material towards the purification of waste water. The K-IDA fiber was first characterized by the instrumental techniques like Fourier transform infrared (FTIR) analysis, elemental analysis (CHNSO), and scanning electron microscopy (SEM). On testing for the biosorption, we found that the K-IDA has an increment in the adsorption of $\mathrm{Cu}^{2+}$ ions as compared against the untreated fiber. The $\mathrm{Cu}^{2+}$ ions adsorption onto K-IDA fits very well with the Langmuir model and the adsorption maximum achieved to be $91.74 \mathrm{mg} / \mathrm{g}$. Further, the adsorption kinetics observed to be pseudo second-order kinetics model and the $\mathrm{Cu}^{2+}$ ions adsorption is a spontaneous endothermic process. The desorption study indicates a highest percentage of $\mathrm{Cu}^{2+}$ of $97.59 \%$ from K-IDA under $1 \mathrm{M} \mathrm{HCl}$ solution against $\mathrm{H}_{2} \mathrm{SO}_{4}(72.59 \%)$ and $\mathrm{HNO}_{3}(68.66 \%)$. The reusability study indicates that the efficiency did not change much until the 4th cycle and also providing enough evidence for the engagement of our biodegradable K-IDA fiber towards the removal of $\mathrm{Cu}^{2+}$ ions in real-time waste water samples obtained from the electroplating and wood treatment industries.
\end{abstract}

Keyword : Surface modification; Modified kenaf fiber; Waste water treatment 